\title{
IV. SCHLUMBERGER WELL-LOG EQUIPMENT AND THE ERICSON-VON HERZEN TEMPERATURE PROBE USED DURING DEEP SEA DRILLING PROJECT LEG 50
}

\author{
Robert E. Boyce, Deep Sea Drilling Project, Scripps Institution of Oceanography, La Jolla, California
}

\section{INTRODUCTION}

During Leg 50 of the Deep Sea Drilling Project (DSDP/IPOD), we used the Schlumberger Ltd. wireline well logging tools, and the Ericson-von Herzen Temperature Probe.

The Schlumberger logs were grouped in each lowering operation as follows:

1) Borehole Compensated Sonic Log (BHC), Caliper (unsuccessful), Gamma Ray (GR), and Maximum Reading Thermometer (MRT).

2) Compensated Neutron Log (CNL), Compensated Formation Density Log (FDC), GR, and MRT.

3) Dual Induction Log (DIL), Laterolog-8, GR, and MRT.

4) High Resolution Temperature Log (HRT).

These tools and various problems associated with their use are discussed below. Investigators may obtain the following logging data from the DSDP Data Repository:

1) Ozalid copies of original analog records at scales of $1: 200$ and $1: 1000$.

2) The analog records for Hole 415, which were not recorded on magnetic tape at the time of logging, were digitized and placed on magnetic tape by Schlumberger Ltd.; each original log is available on magnetic tape. The GR was run singly in Hole $415 \mathrm{~A}$ and was recorded on magnetic tape at the drill site.

3) The BHC, GR (one tape), CNL-FDC, GR, (two tapes), and DIL, Laterolog-8, and GR (one tape) for Hole 416 were recorded on magnetic tapes at the drill site. The HRT analog record was later digitized and placed on magnetic tape by Schlumberger Ltd.

4) The Hole 415 BHC, CNL, FDC, DIL, Latero$\log -8$, and GR are all plotted to a single depth file adjusted to the same depth using GR for stratigraphic control by Schlumberger Ltd., and all data are available on a single Schlumberger Ltd. standard library tape. An additional standard library tape is available, which is corrected for borehole environment. Environmental conditions, assumptions, and tool problems are given in Table 1. These "borehole environment" corrections are the borehole-related adjustments in Schlumberger's (1972b) "Log Interpretation Charts."

5) The Hole 416A BHC, CNL, FDC, DIL, Latero$\log -8$, and GR are also available as a Schlumberger standard library tape and a standard library tape corrected for the borehole environment (chart corrections in Schlumberger, 1972b, are applied). Assumptions, tool problems, and environmental data are listed in Table 1.
TABLE 1

Tools, Abbreviations, Caliper Problems, Estimated Hole Diameter, and Estimated Temperature Gradient Within the Sea Floor

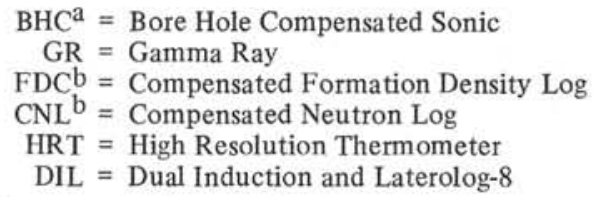

Drill bit diameter is 10 inches, therefore, hole diameter is probably 12 inches.

Temperature at the sea floor is $3.0^{\circ} \mathrm{C}$ with increasing gradient of $3.0^{\circ} \mathrm{C} / 100 \mathrm{~m}$ below the sea floor.

The logs were taken from a ship where the drill rig floor is 10 meters above sea level. Site 415 was in the ocean and had a water depth of 2794 meters, and 416 had a water depth of 4191 meters.

${ }^{\mathrm{a}}$ Caliper with sonic was not run.

${ }^{\mathrm{b}}$ Caliper with FDC-CNL was not run. The caliper and eccentralizing springs, which are normally used in the FDC-CNL logging combination, cannot be used with our logging combination because of our (DSDP's) pipe restrictions. Only a single bow spring was present at the bottom of the FDC tool, therefore, if the hole is verti$\mathrm{cal}$ then the CNL data are questionable as the CNL tool may not be securely held against the side of the hole.

\section{NATURAL GAMMA RADIATION}

We used a Gamma Ray Log (Schlumberger identification number SGT-EA), $3-3 / 8$ inches $(8.57 \mathrm{~cm})$ in diameter, during Leg 50 . It has a scintillation detector which is 6 inches $(15.2 \mathrm{~cm})$ long. The GR data are in American Petroleum Institute (API) units (American Petroleum Institute, 1959). The GR detects natural gamma radiation emitted primarily from potassium, thorium series, and uranium-radium series contained in the formation. Carbonate and sandstone, without potassium feldspars, generally emit very little natural gamma radiation compared with clay and shale formations which adsorb radioactive isotopes as ions. Therefore, the GR is primarily used to distinguish shale from nonshale formations. The GR tool, problems in interpreting and characteristics of the data, such as time constant and logging speed are discussed in Lynch (1962), Schlumberger (1972a, b) and Kokesh (1951).

The GR (with the BHC, DIL, and FDC-CNL Logs) was run at $30 \mathrm{ft}(9.14 \mathrm{~m})$ per minute at Holes 415 and $416 \mathrm{~A}$; the GR time constant was 2 seconds. At Hole $415 \mathrm{~A}$, a single GR was run at $20 \mathrm{ft}(6.10 \mathrm{~m})$ per minute and with a time constant of 3 seconds. Because the GR was run inside the drill string, the slower logging speed and longer time constant were used to statistically enhance the data. In addition, the shipboard analog 
data at Hole 415A were presented at an expanded API scale.

Investigators studying the single deep GR run at Hole 415A should note the following:

1) from 0 meters to 73 meters the GR was shielded from the formation by the drill pipe plus a $40.6-\mathrm{cm}$ diameter casing with the re-entry cone at the surface;

2) from 73 meters to 330 meters the pipe plus 29.8-cm-diameter casing was between the GR and the formation;

3) from 330 meters to 395 meters the drill pipe was between the GR and the formation;

4) from 795 to 809 meters heavy wall drill pipe was between the GR and the formation;

5) from 809 meters to total depth the GR was separated from the formation by the drill collar, with bumper subs at 837 meters to 847 meters and 874 meters to 880 meters. If the bumper subs are open, they act as a "window" in the drill collar and give higher gamma counts.

Pipe joints occur along the 7 -inch $(17.8-\mathrm{cm})$ pipe, at 9.5-meter intervals. These joints are extra thick and thus attenuate the GR tool response, which can be seen on the log as distinct low GR counts at 9.5-meter intervals.

\section{SOUND VELOCITY}

During Leg 50, we ran the Borehole Compensated Sonic (BHC) Log (Schlumberger identification $\mathrm{SLC} / \mathrm{SLS}-\mathrm{KB})$, which is $3-3 / 8$ inches $(8.57 \mathrm{~cm})$ in diameter. It was combined with a caliper (Schlumberger identification MCD) which was supposed to be 3-3/8 (8.57 $\mathrm{cm}$ ) inches in diameter. This caliper was also intended to be the centralizer for the BHC tool. We discovered, however, that the caliper would not pass through a $3-15 / 16$-inch $(10.00 \mathrm{~cm})$ opening near the end of the drill string and the BHC was run without it. Thus the Leg 50 logging data have no hole-caliper data.

The BHC tool measures compressional-sound velocity in units of microseconds per foot $(30.5 \mathrm{~cm})$. The principle of the tool and data interpretation characteristics are described in Schlumberger (1972a), Kokesh et al. (1965), Morris et al. (1963); "noise" and "cycle skipping" are discussed in Lynch (1962). The two receivers of the BHC tool were separated by $2 \mathrm{ft}(61 \mathrm{~cm})$ and the logging speed was $30 \mathrm{ft}(9.14 \mathrm{~m})$ per min.

The BHC tool can place integrated travel-time tick marks down the record for the entire length of the hole. By adding all the time ticks for a given depth interval and dividing that value by the length of the interval, one can obtain an integrated velocity for that interval. Approach this type of data, however, with caution. The BHC tool did not have a centering device; thus the data have noise (high-velocity spikes) (Lynch, 1962) and the integrated time may be inaccurate. Note also any lowvelocity spikes (cycle skipping, Lynch, 1962), which would also result in inaccurate integrated time ticks.

\section{FORMATION WET-BULK DENSITY}

During Leg 50 we used the Compensated Formation Density $\log$ (FDC) which is $3-1 / 2$ inches $(8.89 \mathrm{~cm})$ in diameter (Schlumberger identification PGC-F; PGS-F).
This tool is normally held against the side of the hole by two eccentralizing arms, and in addition normally has a caliper. Because the inside diameter of DSDP's pipe is $3-15 / 16$ inches $(10.00 \mathrm{~cm})$, we could not run the caliper or the upper eccentralizer and simply assumed a nominal hole diameter of 12 inches $(30.5 \mathrm{~cm})-$ appropriate for a 10 -inch $(25.4 \mathrm{~cm})$ bit. A single bowspring at the bottom of the tool kept it against the side of the hole. At Site 416 this bow-spring collapsed; thus the data are not quantitative and should be treated subjectively. The FDC analog field data are calibrated for density in a limestone matrix with fresh water in the pores. The logging speed was $30 \mathrm{ft}(9.14 \mathrm{~cm})$ per minute and we used a 2 -second time constant.

The FDC tool measures wet-bulk density using a gamma-ray back-scattering technique. Wet-bulk density is the ratio of the mass of water-saturated (if in situ gas is not present) formation to its volume, expressed as grams per cubic centimeter. This technique, description of the logging tool, and interpretation characteristics, assumptions, and precautions are discussed in Schlumberger (1972a, 1974), Wahl et al. (1964), Sherman and Locke (1975). Additional discussions of general principles are also found in Baker (1957) and Lynch (1962).

\section{FORMATION POROSITY}

On Leg 50 we used the Compensated Neutron Log $(\mathrm{CNL})$, which is $3-3 / 8$ inches $(8.57 \mathrm{~cm})$ in diameter (Schlumberger identification CNT-A, bare). This tool is designed to be decentralized in the hole. The decentralizing spring, however, was removed as it did not fit through the pipe opening. The GR, CNL, and FDC tools were combined into a single string, and the only eccentralizer attached was below the FDC tool, which was below the CNL tool (Figure 1). According to Schlumberger personnel (personal communication) the FDC-CNL tools will ride against the hole wall in the proper geometric position if the hole is not vertical. The CNL will pull away from the side of the hole if the hole is vertical. The CNL data from Hole 415 showed a porosity higher than the scale on the CNL tool. This apparently was caused by the tool pulling away from the side of the hole, which was misconstrued as additional formation porosity.

The CNL data at Hole 416A are not quantitative, because the lower eccentralizer spring on the FDC-CNL tool broke and the tool may have oscillated horizontally in the hole, thus invalidating the data or at least requiring that they be treated subjectively.

The CNL is a thermal-neutron detection tool. (A more desirable epithermal-neutron tool could not be used with DSDP's pipe restrictions.) The thermal neutrons emitted from the tool are primarily, but not entirely, attenuated by collisions with $\mathrm{H}^{+}$protons (same mass as neutron) in the pore water. The tool can measure an approximate porosity with proper formation matrix corrections. Porosity is the ratio of the volume of pore space in sediment or rocks to the volume of the water-saturated (if in situ gas is not present) sediment or rock, expressed as a percentage. The analog data are in per cent units of porosity calibrated for a 


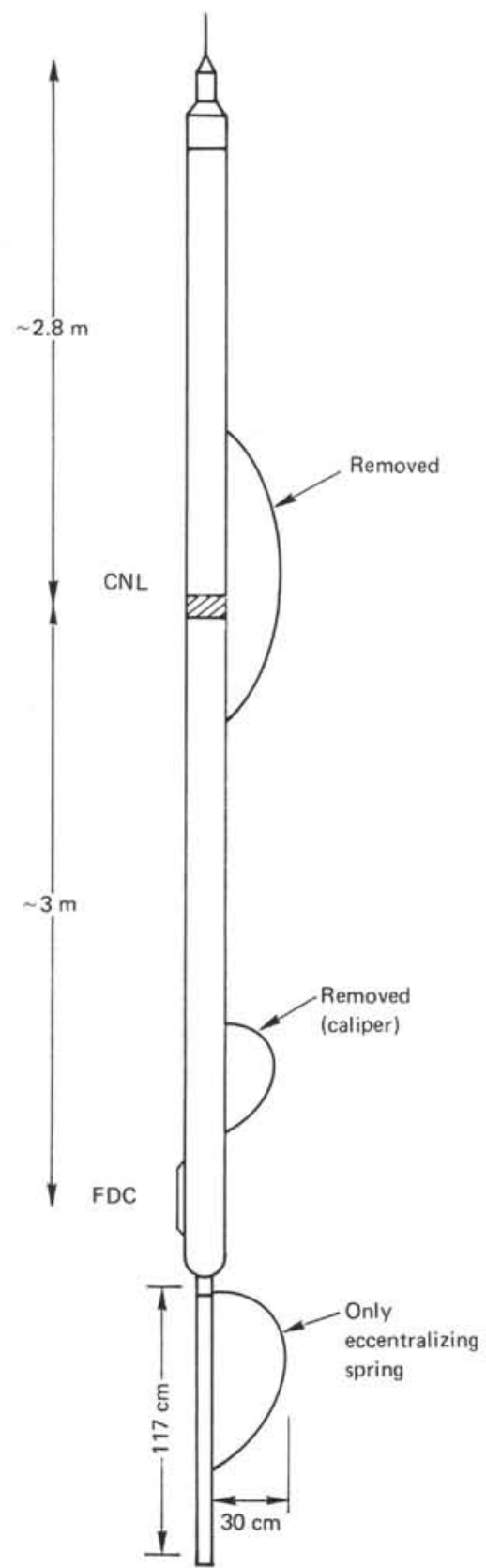

Figure 1. The CNL-FDC device, not drawn to scale, showing location of the only eccentralizer at the bottom of the FDC tool.

limestone matrix with fresh pore water. The tool was run at $30 \mathrm{ft}(9.14 \mathrm{~m})$ per minute using a 2 -second time constant. Fresh mud was used in these holes. The CNL tool, the techniques, principles, assumptions, precautions, and interpretation characteristics are discussed in Schlumberger (1972a), Alger et al. (1972), and Sherman and Locke (1975).

\section{ELECTRICAL RESISTIVITY AND CONDUCTIVITY}

During Leg 50 we used the Dual Induction (DIL) and Laterlog- 8 tools, which are $3-3 / 8$ inches $(8.57 \mathrm{~cm})$ in diameter (Schlumberger identification DIT-B). The deep-induction and medium-induction logs measure electrical conductivity with vertical resolutions of about 60 inches $(152 \mathrm{~cm})$ and 40 inches $(102 \mathrm{~cm})$, respectively. These resolutions vary depending upon the formation's electrical resistivity and resistivity contrasts in the formation. Penetration ( $50 \%$ of signal) away from the hole is about 65 inches $(165 \mathrm{~cm})$ and 30 inches $(76 \mathrm{~cm})$, for the respective deep and medium logs (Schlumberger, 1972a).

Electrical conductivity is the ability of a cube of geologic material to conduct electricity when a voltage is applied; this is reported as mho- $\mathrm{m}^{2} /$ meter which reduces to mho-m. Electrical resistivity is the inverse of the conductivity value and is reported as ohm-m. Conduction is in the form of (1) electron conduction in solid minerals and (2) electrolite conduction in the pore water (see Keller and Frischknecht, 1966, for detailed discussions). Normally, in materials with salinities equivalent to sea water, the electrical conduction is primarily through the pore water, and thus conductivity and resistivity are related to the porosity of the geologic material. Conduction, however is also influenced by conductive solid minerals, temperature, and salinity.

The Laterlog- 8 is a focused electrical log, which measures electrical resistivity with a vertical resolution of about 24 inches $(61 \mathrm{~cm})$. Penetration, 50 per cent of signal, is very shallow (approximately 12 inches, $31 \mathrm{~cm}$ ) and is affected by the resistivities and geometrical dimensions of all the media around the device (Schlumberger, 1972a).

Data for each electric log are presented in units of electrical resistivity on a logarithmic scale (from 0.5 to $1000 \mathrm{ohm}-\mathrm{m})$. The logging speed was $30 \mathrm{ft}$. $(9.14 \mathrm{~m})$ per minute and fresh mud was used in the holes. At Hole 415 the "Baryte" mud was fresh: resistivity $=1.77$ ohm-m at $84^{\circ} \mathrm{F}\left(29^{\circ} \mathrm{C}\right)$, density $=10.9 \mathrm{lb} / \mathrm{gal}(1.31$ $\mathrm{g} / \mathrm{cm}^{3}$ ), and viscosity $=73$ centiposes. At Hole $416 \mathrm{~A}$ the mud was fresh: resistivity $=1.04 \mathrm{ohm}-\mathrm{m}$ at $75^{\circ} \mathrm{F}$ $\left(24^{\circ} \mathrm{C}\right)$, mud fluid resistivity $=0.85$ ohm-m at $75^{\circ} \mathrm{F}$ $\left(24^{\circ} \mathrm{C}\right)$, resistivity mud cake $=1.21 \mathrm{ohm}-\mathrm{m}$ at $75^{\circ} \mathrm{F}$ $\left(24^{\circ} \mathrm{C}\right)$, density $=9.1 \mathrm{lb} / \mathrm{gal}\left(1.09 \mathrm{~g} / \mathrm{cm}^{3}\right)$, and viscosity $=(?)$.

Discussions of these electric logging tools, assumptions, precautions, and interpretations are given in Doll (1949, 1951); Moran and Kunz (1962); and Schlumberger (1972a, b). Keller and Frischknecht (1966) and Lynch (1962) also discuss the various types of tools.

\section{TEMPERATURE}

\section{High Resolution Temperature Log}

On Leg 50 we used the High Resolution Temperature $\log (\mathrm{HRT})$, which is $1-11 / 16$ inches $(4.28 \mathrm{~cm})$ in diameter (Schlumberger identification HTT-B). The HRT's precision is within $\pm 0.1^{\circ} \mathrm{C}$, and it has a nearly instantaneous equilibrium period. The HRT has an accuracy of \pm 2 to 3 per cent of the temperature range that is calibrated, a range of $0^{\circ} \mathrm{C}$ to $100^{\circ} \mathrm{C}$ on Leg 50. It has a total temperature range of $0 \_C$ to $176 \_C$. The HRT is a resistance thermometer and is discussed briefly in Schlumberger (1974) and in Lynch (1962). 
At Hole 416A, we measured temperature versus depth in the water column (through pipe) to about 425 plus meters below the sea floor. We measured the temperature on the way down, but some artifacts are in the data. The HRT tool would frequently stick in the hole, then suddenly drop. This particularly occurred between 425 meters and 459 meters; the HRT would not go any deeper than 459 meters. Logging speed was erratic and relatively slow because the tool would stick in the hole if lowered too fast. In the upper part of the hole the temperature was measured through the drill pipe plus the cone and casing.

The following drilling sequence is briefly presented so that investigators can properly interpret the temperature-log data. The HRT was run after a long and complicated operation (see Site 416 Report, this volume, for details). Hole 416A spudded in at 1119 hours, 1 October. The hole was drilled, cored, and re-entered several times and we reached 1605 meters below the sea floor at 1140 hours, 26 October. We stopped drilling, pulled the pipe out of the hole at 1405 hours, 26 October, and at 2155 hours we returned to port. We returned to the site and re-entered the hole at 0537 hours on 31 October. At about 0400 hours, 1 November, new formation was penetrated to 1624 meters. We penetrated no farther. Following various problems and re-entry attempts, the bit was 80 meters above 1624 meters and we stopped drilling the hole at 0745 hours on 3 November. Three hundred barrels of mud was placed in the hole and the first suit of logging tools (sonic tool) began at $\mathbf{2 0 2 5}$ hours on 3 November. On about 0100 hours, 6 November, the HRT Log was begun. It was finished and on deck at 0510 hours, 6 November.

\section{Maximum Reading Thermometer (MRT)}

This tool records only the maximum temperature in the water column or drill hole and it has a range of $0^{\circ} \mathrm{C}$ to $177^{\circ} \mathrm{C}$ and an accuracy of about $1{ }^{\circ} \mathrm{C}$ to $2^{\circ} \mathrm{C}$. Equilibrium time for the thermometer is about 10 minutes. This tool records useful data only when downhole temperatures are significantly greater than the ocean water temperature $\left(\sim 21^{\circ} \mathrm{C}\right)$. Unfortunately this was not the case on Leg 50, during which water temperatures were about $22^{\circ} \mathrm{C}$. The thermometer is normally run with the sonic, density-neutron, and electric logs and is noted as the maximum recorded temperature on the analog record.

\section{Ericson-von Herzen Temperature Probe}

We attempted to use the Ericson-von Herzen Temperature Probe in Hole 415. Only one of three attempts was successful (Figure 2). The Ericson-von Herzen Temperature Probe measured $17.5^{\circ} \mathrm{C}$ at 452 meters depth below the sea floor in Hole 415 (Erickson, personal communication), and by assuming a $3.0^{\circ} \mathrm{C}$ seafloor temperature we arrived at an average temperature gradient of $\sim 32^{\circ} \mathrm{C} / 1000$ meters. This gradient compares well with an "average" gradient of $30^{\circ} \mathrm{C} / 1000$ meters recorded at Hole $416 \mathrm{~A}$ with the $\mathrm{HRT}\left(3.15^{\circ} \mathrm{C}\right.$ at sea floor and $17.4^{\circ} \mathrm{C}$ at $425 \mathrm{~m}$ depth below the sea floor).

\section{REFERENCES}

Alger, R.P., Locke, S., Nagel, W.A., and Sherman, H., 1972. The dual-spacing neutron $\log -\mathrm{CNL}, J$. of Petrol. Technology, v. 24, p. 1073-1083.

American Petroleum Institute, 1959. Recommended practice for standard calibration and form for nuclear logs, API RP 33, Sept.

Baker, P.E., 1957. Density logging with gamma rays, Transactions, $A I M E$, v. 210, p. 289-294.

Doll, H.G., 1949. Introduction of induction logging and application logging of wells drilled with oil base mud, Transactions, AIME, v. 186 , p. 148-164.

1951. The Laterolog: A new resistivity logging method with electrodes using an automatic focusing system, Transactions, AIME, v. 192, p. 305-316.

Keller, G.V. and Frischknecht, F.C., 1966. Electrical methods in geophysical prospecting: New York (Pergamon Press).

Kokesh, F.P., 1951. Gamma-ray logging, The Oil and Gas Journal, v. 50, p. 284-290.

Kokesh, F.P., Schwartz, R.J., Wall, W.B., and Morris, R.L., 1965. A new approach to sonic logging and other acoustic measurements, J. of Petrol. Technology, v. 17, p. 282286.

Lynch, E.J., 1962. Formation evaluation: New York (Harper \& Row).

Moran, J.H. and Kunz, K.S., 1962. Basic theory of induction logging and application to study of two-coil sondes, Geophysics, v. 27, p. 829-858.

Morris, R.L., Grine, D.R., and Arkfeld, T.E., 1963. The use of compressional and shear acoustic amplitudes for the location of fractures: 38th Annual Fall Meeting of the Society of Petroleum Engineers of AIME: New Orleans, La., 6-9 October 1963, Paper SPE 723, p. 1-13.

Schlumberger, 1972a. Log interpretation: V.I. principles: New York (Schlumberger Ltd.). 1972b. Log interpretation charts: New York (Schlumberger Ltd.). , 1974. Log interpretation: V.II. applications: New York (Schlumberger Ltd.).

Sherman, H. and Locke, S., 1975. Effect of porosity on depth of investigation of neutron and density sondes, 50th Annual Fall Meeting of the Society of Petroleum Engineers of AIME: Dallas, Texas, 28 Sept. to 1 Oct. 1975, Paper SPE 5510 , p. $1-12$.

Wahl, J.S., Tittman, J., and Johnstone, C.W., 1964. The dual spacing formation density log, J. of Petrol. Technology, v. 16 , p. 1411-1416. 


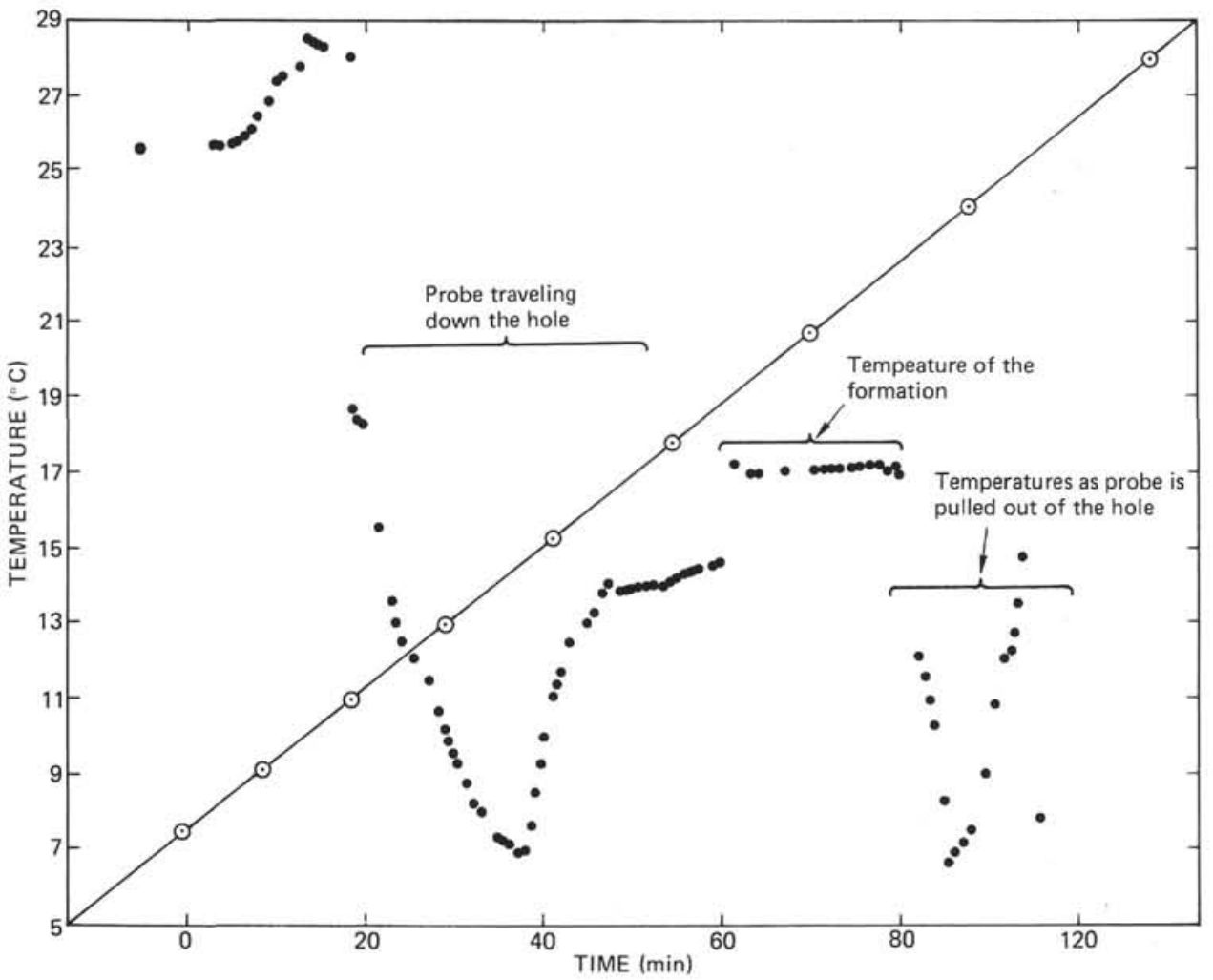

Figure 2. Hole 415: Ericson-von Herzen temperature probe at 452.5 meters; temperature versus time. Ericson's (personal communication) interpretation of Ericsonvon Herzen Temperature Probe data. 